\title{
CASTIGO Y CONTROL: LA VIGILANCIA COLECTIVA ARMADA TERRITORIAL EN MÉXICO, EL CASO DE TIERRA CALIENTE (MICHOACÁN)
}

\author{
PUNISHMENT AND CONTROL: COLLECTIVE ARMED TERRITORIAL SURVEILLANCE IN \\ MEXICO, THE CASE OF TIERRA CALIENTE (MICHOACÁN)
}

\section{Miguel Ángel Vite Pérez ${ }^{1}$}

\section{Resumen}

El artículo se basó en argumentos teóricos para construir una explicación acerca de la aparición de la vigilancia armada en algunas comunidades rurales ubicadas en el estado de Michoacán (México). Por eso, partimos de la existencia de una representación social, donde el delito ha sido interpretado como un peligro para la vida y la propiedad. Esto permitió analizar parte del discurso de algunos líderes de la autodefensa armada de Michoacán, caracterizado por una continuidad entre su discurso y el del gobierno mexicano, donde apareció la criminalización de algunas actividades ilegales locales.

Por otro lado, se analizó la relación entre la idea de territorios ilegales o zonas grises y las acciones de autodefensa armada contra la criminalidad, como una manera de crear una explicación, que no comparte el punto de vista acerca de la debilidad del Estado mexicano, considerada como causa del aumento de las actividades de la delincuencia a nivel regional.

Palabras clave: Vigilancia Armada; Zonas Grises; Territorios Ilegales; Aparatos; Dispositivo.

\begin{abstract}
The article was based on theoretical arguments to construct an explanation about the emergence of armed surveillance in some rural communities located in the state of Michoacan (Mexico). That is why we start from the existence of a social representation, where the crime has been interpreted as a danger to life and property. This allowed to analyze part of the speech of some leaders of the armed self-defense of Michoacán, characterized by a continuity between his speech and the one of the Mexican government, where the criminalization of some illegal local activities appeared.

On the other hand, the relationship between the idea of illegal territories or gray areas and actions of armed self-defense against crime was analyzed as a way of creating an explanation that does not share the point of view about the weakness of the Mexican State, considered to be the cause of the increase in crime activities at the regional level.
\end{abstract}

Keywords: Armed Surveillance; Gray Zones; Illegal Territories; Apparatus; Device.

\footnotetext{
${ }^{1}$ Doctor en sociología por la Universidad de Alicante, España. E-mail: miguelviteperez@yahoo.com.mx
} 


\section{INTRODUCCIÓN}

El 24 de febrero de 2013, en la región de Tierra Caliente (Michoacán) aparecieron grupos armados, integrados por miembros de algunas comunidades de la región, cuyo objetivo fue el combatir a la organización delictiva regional, llamada Los Caballeros Templarios².

Por tal motivo, aquéllos grupos armados se llamaron así mismos autodefensas y comenzaron a realizar funciones de vigilancia armada en diversas comunidades que integran la región de Tierra Caliente (ver mapa 1).

\section{Mapa 1}

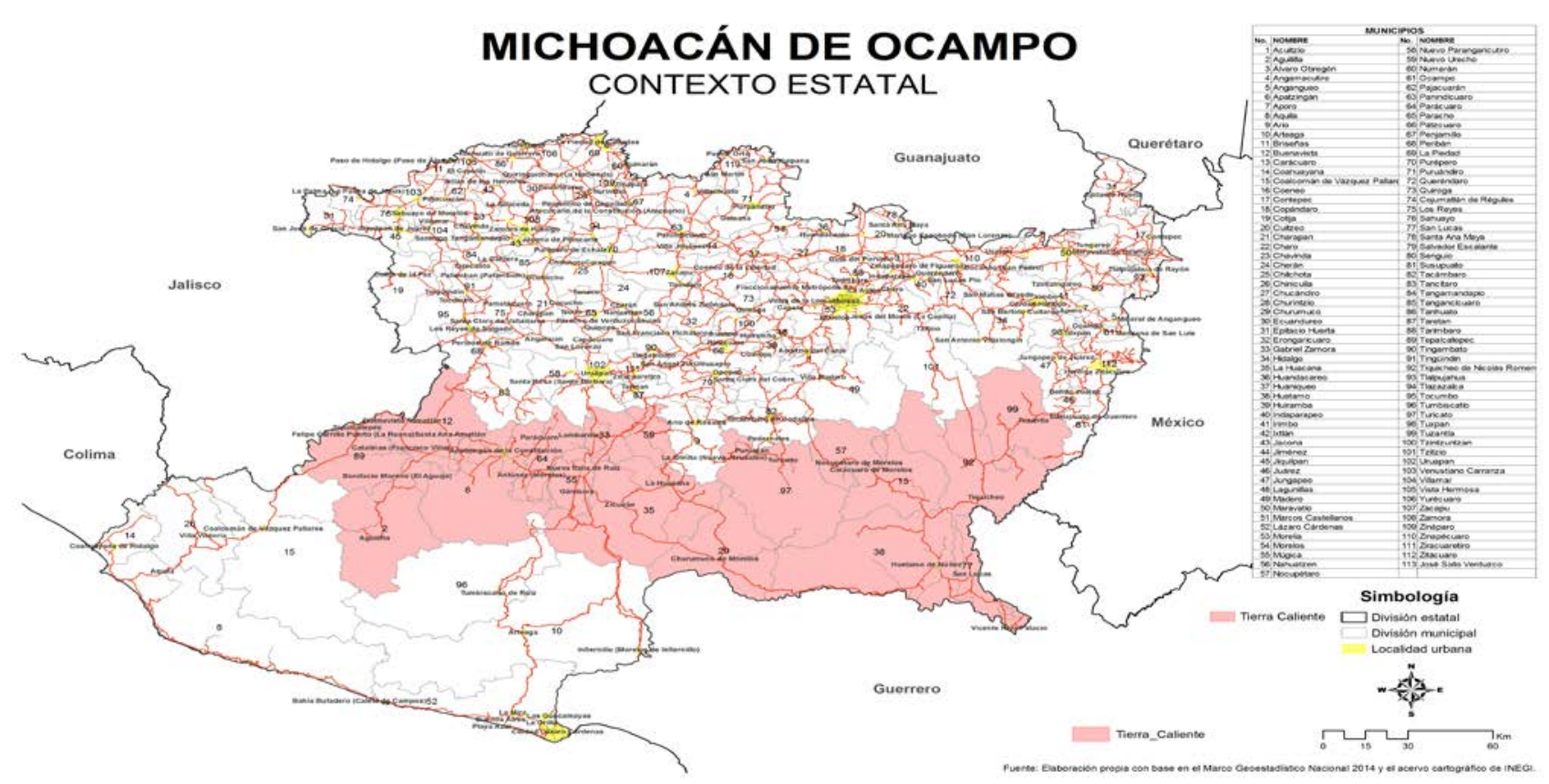

Pero ése hecho se manifestó en un contexto sociopolítico de internacionalización de la ideología de la seguridad nacional, desde donde se ha percibido como una amenaza nacional, la transnacionalización de las actividades del tráfico ilegal de drogas por parte del crimen organizado.

Por ello, la vigilancia armada territorial no sólo fue resultado de la pérdida del control estatal sobre algunas partes del territorio nacional, sino de la existencia de una criminalización

${ }^{2}$ El 24 de febrero es una fecha cívica mexicana que celebra el día de la bandera nacional, lo que tiene un significado simbólico, es decir, cultural pero su uso de parte de las autodefensas de Tierra Caliente (Michoacán) fue para legitimar su acción armada contra los grupos criminales vinculados con el problema nacional de la inseguridad pública (Véase, GOLUBOV, 2015). 
realizada de manera general desde el Estado contra la población local, que participaba de manera directa o indirecta en los negocios ilegales de la región (BAUMAN, 2008: 14-16, BAUMAN, 2013: 21-27, WACQUANT, 2000).

En este sentido, gobernar un territorio ilegal depende de los intereses particulares de los grupos armados, donde su control se caracteriza de manera particular por ejercer su soberanía a través de la muerte. Es decir, por medio de un régimen identificado con la necropolítica (MBEMBE, 2011).

De acuerdo con MBEMBE (2011: 42-46), soberanía significa ocupación territorial, pero también capacidad para decidir sobra la vida de los que han dejado de tener valor y que, al mismo tiempo, tienen una presencia importante en el territorio.

Por tal motivo, algunas funciones de gobierno se realizan a través de grupos privados que deciden quién debe de vivir y quién debe de morir, lo que es dictado por la dinámica de los negocios privados ilegales (HONNETH, 2010: 26-27).

En México, la anterior situación ha sido interpretada a través del uso de una representación social de la inseguridad pública, donde se ha identificado a la economía informal o ilegal como un peligro para la vida y la propiedad (ESCALANTE, 2012) ${ }^{3}$.

En algunos casos, la ideología de la inseguridad pública ha servido como legitimación a la organización vecinal o comunal armada, cuya acción se ha dirigido a combatir a los criminales locales y regionales ${ }^{4}$.

Desde otro punto de vista, la vigilancia ${ }^{5}$ armada mexicana es un dispositivo ${ }^{6}$ que fue usado para evitar el despojo de patrimonios, y a su vez, para la protección de las vidas de los integrantes de las comunidades, en los territorios donde se realizan los diversos negocios,

\footnotetext{
${ }^{3}$ En diciembre de 2014, 7 de cada 10 mexicanos que vivían en ciudades tenían miedo a la inseguridad creada por los delincuentes, según la Encuesta Nacional de Seguridad Pública Urbana, elaborada por el Instituto Nacional de Estadística, Geografía e Informática (INEGI) (GONZÁLEZ, 2015: 3).

${ }^{4}$ El 31 de diciembre de 2013, las autodefensas subieron un video en YouTube, que titularon: "Resumen 2013 de las autodefensas Valor por Michoacán". Donde se puede observar, durante 11 minutos con 34 segundos, sus marchas, protestas, sus vehículos baleados y los retratos de las personas fallecidas que pertenecían a las autodefensas (SÁNCHEZ, 2014: 45).

${ }^{5}$ La vigilancia armada es una práctica social que puede estar complementada por el uso de las tecnologías electrónicas y también por la utilización de las armas en un contexto de riesgo y miedo asociado a las acciones de la delincuencia (TIRADO y DOMÉNECH, 2006: 23).

${ }^{6}$ La idea de dispositivo hace referencia a un acuerdo o a un arreglo para la realización de una acción individual o colectiva, que busca cumplir con objetivos de control y vigilancia (AGAMBEN, 2009). En este caso, el dispositivo de la vigilancia tiene como propósito identificar y perseguir a personas consideradas como sospechosas por sus creencias, y sobre todo en un contexto de miedo y temor, por dedicarse a las actividades ilegales relacionadas con el crimen. Dichas personas han sido convertidas en culpables por haber afectado la vida y el patrimonio de la comunidad o grupo (Véase, MATTELART y VITALIS, 2015: 26).
} 
relacionados con el tráfico de drogas, acompañados también de la explotación comercial ilegal de algunos recursos naturales localizados en los mismos.

Pero la violencia ejercida por los narcos en Tierra Caliente no es ajena a la violencia cotidiana de sus habitantes, lo cual se ha manifestado como luchas por la tierra, el poder político y también contra la vida de las mujeres (GLEDHILL, 2017: 136).

Lo anterior, según GLEDHILL (2017: 149), ha reproducido una subcultura de la violencia cuya base no sólo ha sido la extorsión generalizada y la impunidad, sino la articulación de las relaciones entre organizaciones criminales y actores económicos y políticos legitimados por las instituciones estatales.

Con otras palabras, la violencia armada desarrollada por grupos particulares en la región de Tierra Caliente ha sido negada por las autoridades locales y federales porque argumentan que es más un resultado de una disputa entre grupos de narcotraficantes rivales y no derivado de una resistencia de sus pobladores ante acciones legales e ilegales, por ejemplo, de despojo de sus tierras y recursos naturales para favorecer, finalmente, a los intereses económicos privados.

En este sentido, el artículo tiene como objetivo analizar algunos elementos de los discursos construidos por algunos de los participantes en el conflicto y que han sido parte también de la reproducción social de los territorios ilegales; lo que ha terminado por justificar o reforzar el punto de vista punitivo del Estado mexicano, en otras palabras, ha legitimado el uso de la violencia armada comunitaria contra las organizaciones criminales (GILBERT, 2012: 47-49).

Por eso, me auxilie de algunos periódicos considerados, y de acuerdo con ALEXANDER (2006: 193-195), como una expresión del discurso de actores sociales en una esfera civil organizada a través de valores ideales, que a su vez, muestran sus limitaciones reales para su concreción; sobre todo, que estos últimos pueden negar a los primeros, por ejemplo, al reproducir la exclusión en el acceso democrático a las ventajas sociales.

De esta manera, el artículo se dividió en tres partes. En la primera se estudió el lazo establecido entre el control social de la delincuencia por medio del uso de la tecnología de la vigilancia y algunas consecuencias sobre la organización de la vida social. Mientras, en la segunda parte, se analizó lo que ha sucedido en algunas localidades rurales de Michoacán, donde las acciones del gobierno y de las autodefensas, reforzaron el uso legítimo de la violencia armada para combatir a Los Caballeros Templarios, partiendo del siguiente supuesto: la violencia armada se legitima cuando se ejerce contra los que han sido clasificados como enemigos del orden social. Finalmente, se presentan las conclusiones sobre el tema estudiado. 


\section{EL USO SOCIAL DE LA VIGILÂNCIA}

El control estatal del territorio mediante una organización política administrativa, que regulaba normativamente los procesos sociales y económicos, permitió la reproducción de un orden social vigilado.

Por ello, el control estatal vigilado ha significado más una reactivación de su función punitiva contra la amenaza que representa la inseguridad pública para la cohesión social (DE GIORGI, 2006: 53-55).

Por otro lado, el uso de la tecnología de la vigilancia estatal se ha transformado en un medio para mejorar su función de control sobre la criminalidad en algunos territorios ilegales o zonas grises (MALDONADO, 2010: 23; ILLADES y SANTIAGO, 2014: 12; AUYERO, 2007).

Sobre todo, porque existe una tendencia mundial que identifica la vigilancia estatal con la existencia de una vigilancia de lo interno, donde se ha señalado como enemigos a algunos individuos que forman parte de la organización social, lo que también depende del estigma social negativo, que se les ha conferido desde el poder político o a través del imaginario social (WAJMAN, 2011:16).

Según WAJMAN (2011:19-21) "ver sin ser visto" es parte de la civilización contemporánea de la mirada y que ha posibilitado el nacimiento del ojo universal o absoluto, apoyado en las videocámaras o tecnología de la vigilancia, instaladas en los espacios públicos (MATTELART, 2014: 205; DELEUZE, 1995: 169-176; MARZANO, 2011: 12-29).

En consecuencia, las instituciones estatales mantienen el objetivo de moldear los actos de los individuos mediante el uso de instrumentos de control y de coerción, pero ahora están apoyados, insisto en la tecnología de la vigilancia (BERGER, 2013: 130-131; MATTELART, 2014: 206).

La vigilancia como un control de los comportamientos sociales criminales ha establecido un conocimiento derivado de la transformación de las instituciones en aparatos y redes (AGAMBEN, 2009: 2-3).

Por eso, AGAMBEN (2009: 12-14) argumentaba que tanto los aparatos como las instituciones gestionaban, gobernaban, controlaban y orientaban, de acuerdo con sus propósitos particulares de utilidad, los comportamientos individuales.

Sin embargo, como cosas los aparatos solamente capturan, interceptan determinados gestos, comportamientos, opiniones o discursos de la vida cotidiana. 
Los aparatos crean subjetividades diferenciadas y momentáneas, que dentro del discurso tecnológico, se limita a un problema del uso correcto de los aparatos de parte del usuario. En esta situación, el sujeto sólo importa cuando se transforma en un número telefónico, en una contraseña o en un espectador, al formar parte de los ratings televisivos o de los eventos masivos de entretenimiento.

El estudio de la tecnología como cosa se limita a su uso "correcto", vinculado a un instructivo, sin embargo, como aparato permite hablar de un preparativo para un acontecimiento, lo que conlleva conocimiento sobre el asunto, mientras, que como dispositivo se refiere a una disposición, en otras palabras, a un arreglo, reglamento, administración, cláusula de testamento (DÉCOTE, 2013: 101-107).

En este sentido, y siguiendo el argumento de DÉCOTE (2013: 108-109), la tecnología de la vigilancia ha sido convertida en un dispositivo para controlar y vigilar a las llamadas "clases peligrosas" o "grupos de riesgo", y en consecuencia, no puede ser considerado como un aparato productor de derechos ciudadanos.

Entonces, la tecnología de la vigilancia puede ser una cosa y también un aparato, desde el punto de vista instrumental; sobre todo, cuando ha sido definida solamente por su utilidad en determinados contextos sociales.

Por otro lado, la peligrosidad contra el orden público tiene como principal evidencia empírica a los individuos o grupos peligrosos, estigmatizados por sus creencias religiosas y su cultura, lo que ha convertido a la tecnología de la vigilancia en un dispositivo de control nacional con consecuencias internacionales (FOESSEL, 2011; LYON, 2003)7.

Por ello, en la doctrina de la seguridad transnacionalizada, el territorio ilegal aparece organizado sólo bajo la lógica de la economía criminal local, donde las autoridades y las policías, combinan el terror con el uso de los dispositivos tecnológicos (como videos y grabaciones), que en algunas ocasiones han servido sólo para fortalecer sus lazos con los negocios ilícitos (BAILEY, 2014).

Pero lo que se debe de destacar es que a nivel local o regional el territorio adquiere una importancia debido a que ahí se manifiestan las contradicciones de la economía neoliberal globalizada, y al mismo tiempo, alcanza una validez general la doctrina de la seguridad nacional, que se ha caracterizado, desde un punto de vista general, por la criminalización del narcotráfico y también del fundamentalismo religioso de origen musulmán (KEPEL, 2005: 19-73).

\footnotetext{
${ }^{7}$ Esto se agudizó a raíz de los atentados ocurridos en Nueva York el 11 de septiembre de 2001.
} 
Pero lo que también está sucediendo es un proceso de multiterritorialidad que se refiere solamente a la destrucción y construcción de territorios por causas económicas, sociales y culturales (HAESBAERT, 2011: 29).

La aparición de territorios ilegales es parte de la expansión de una geografía de la desigualdad capitalista, que ha puesto en marcha un proceso de acumulación privada por desposesión de patrimonios individuales y públicos (HARVEY, 2006: 25-29).

Por otro lado, el uso intensivo de la tecnología como dispositivo ha creado una nueva manera de compartir la acción punitiva estatal al combinar las funciones de las fuerzas armadas con las de la policía a través de los llamados drones, es decir, aviones no tripulados que realizan funciones de guerra en los territorios ilegales (JORDÁN y BAQUÉS, 2014).

La vigilancia armada colectiva ha surgido en los territorios ilegales, localizados en los márgenes de los Estados nación o en sus zonas grises, mostrando que el Estado no controla todos los procesos económicos y sociales que se desenvuelven en su territorio ni mucho menos algunas actividades criminales.

En suma, la vigilancia armada regional es una nueva forma de ejercer la función punitiva de manera fragmentada de parte de los diversos grupos sociales ${ }^{8}$, lo que ha significado el fin del monopolio de la violencia ejercida por el Estado mexicano, en un contexto de consolidación de la democracia liberal y del modelo económico neoliberal (FERNÁNDEZ, 2013: 41-51).

Por otro lado, según STAVRIDES (2016: 20) las diferentes maneras de definir y controlar el espacio o territorio dependen también de las construcciones sociales, basadas en valores y experiencias reales significativas; pero vinculadas con el entorno que define identidades, que en una situación de conflicto, pueden convertirse en una defensa no sólo simbólica de los miembros de una comunidad; sino, concreta frente a las amenazas que les podría representar, por ejemplo, las actividades económicas ilegales para su modo de vida.

De esta manera, aparecen los umbrales, territorios donde la identidad cotidiana queda suspendida para dar paso a una situación de tránsito, donde se podría adquirir una nueva, que en el caso de la región de Tierra Caliente, fue englobada bajo palabras clasificatorias, según ESCALANTE (2012: 40-42), como "sicario", "lugarteniente", "halcón", "jefe de plaza”, "cártel”, "autodefensa".

\footnotetext{
${ }^{8}$ Esos grupos vecinales organizan redadas y se informan con habitantes de las diferentes localidades sobre posibles sospechosos de ejercer actividades delictivas para buscar y detener a supuestos criminales, instalando también retenes en las entradas y salidas de la comunidad (Espino, 2016: 35).
} 
Pero ésas palabras clasificatorias fueron también ligadas a las actividades atribuidas, desde el imaginario social, al llamado crimen organizado y a su combate por parte de algunos grupos sociales armados.

En consecuencia, el llamado crimen organizado ha introducido cambios en la región de Tierra caliente al configurar un territorio donde se articulaban las actividades económicas ilegales con las legales, reforzando la imagen histórica de sus habitantes como pobladores proclives a la violencia, en una situación geográfica donde el clima es de un calor extremo (MALDONADO, 2010).

La idea de umbrales territoriales conduce a visualizar a las identidades como encerradas, es decir, encuadradas tanto de manera espacial como temporal, donde las experiencias también particulares de enclave son ajenas al resto del territorio nacional (STAVRIDES, 2016: 41).

Desde la perspectiva descrita, la inseguridad pública de la región de Tierra Caliente es una construcción social, donde convergen las experiencias de las comunidades locales, derivadas de su interacción con los que controlan el negocio del tráfico ilegal de las drogas, aliados con las autoridades (LEMUS, 2015).

Pero el control social territorial a través de los dispositivos tecnológicos ha influido en la creación de prácticas digitales que documentan no sólo protestas y movilizaciones sino que muestran como denuncia situaciones de corrupción y complicidad entre las autoridades y los poderes fácticos identificados con lo ilícito (TRERÉ, 2015).

De acuerdo con TRERÉ (2015: 167-168), la expansión de las prácticas digitales es resultado del uso generalizado de las tecnologías digitales, que ayudan a crear y distribuir de manera económica y rápida, videos en plataformas on line como YouTube y Vimeo.

En el caso de las autodefensas de Tierra Caliente su videoactivismo resultó importante para legitimar sus acciones armadas contra Los Caballeros Templarios en el ciberespacio, aunque, también el líder de Los Caballeros Templarios hizo lo mismo. Esto en realidad mostró el uso generalizado de la tecnología visual para la creación de una subjetividad de denuncia y queja ante el dominio de lo ilegal en la configuración de las relaciones sociales regionales ${ }^{9}$.

Por su parte, lo ilegal al ser el elemento principal en la configuración de las relaciones sociales ha afectado la vigencia normativa de los derechos ciudadanos porque los protagonistas

\footnotetext{
${ }^{9}$ Los videos en las plataformas on line se han convertido en otra manera de fichar a sus protagonistas de parte de las policías por considerarlos sospechosos de un activismo negativo para el poder político y económico (MATTELART y VITALIS, 2015: 45).
} 
de lo ilícito cuando están en conflicto realizan acuerdos informales o recurren a la violencia y no a la ley, aunque, algunas autoridades, junto con algunos policías, pueden participar de acuerdo con sus intereses a favor de alguno de los bandos (AUYERO y BERTI, 2013).

En suma, en la conformación de los territorios ilegales mexicanos ha influido, desde una perspectiva general, la política económica neoliberal por sus consecuencias sociales sobre el bienestar colectivo, y a su vez, por la debilidad de los programas de asistencia social estatales para cumplir con el objetivo de integración social, reproduciendo la exclusión y la ilegalidad como una manera de producir una relativa estabilidad socioeconómica local y regional a través de acuerdos convencionales ${ }^{10}$ (BAYÓN, 2015).

Finalmente, la configuración de una vigilancia armada por medio de las autodefensas comunitarias en Tierra Caliente fue para combatir a Los Caballeros Templarios señalados por los pobladores como la causa de la inseguridad pública regional; pero lo que mostró fue que la legalización de sus acciones no podría realizarse en el marco de la ley sino utilizando dispositivos como las comisiones gubernamentales y también la fuerza letal oficial para normalizar la situación al eliminar supuestamente la causa del conflicto ${ }^{11}$ : Los líderes de los Caballeros Templarios.

\section{LA VIGILANCIA ARMADA COMO APOYO A LA FUNCIÓN PUNITIVA ESTATAL}

En México, a partir de 1982, la introducción de la modernidad económica neoliberal ha sido analizada como una apropiación privada de recursos naturales y de activos públicos, lo que fue interpretado como una pérdida de soberanía o poder de parte del Estado para regular el mercado y los procesos económicos transnacionalizados que ocurrían en el territorio nacional (TELLO e IBARRA, 2012: 63-96).

Sin embargo, durante la vigencia del modelo económico de Sustitución de Importaciones (1940-1982), el protagonista principal fue el Estado que integró a las regiones a través de la expansión de la economía del mercado e impuso a las comunidades rurales nuevas

\footnotetext{
${ }^{10}$ Esto se relaciona con los usos y costumbres que no se encuentran regulados por las normas legales y que han servido para crear gobernabilidad a lo largo de la historia pública mexicana (ESCALANTE, 1992)

${ }^{11}$ El artículo 2 de la Constitución Política de los Estados Unidos Mexicanos permite que las comunidades indígenas se organicen a través de sus usos y costumbres, lo que supuestamente incluye a la seguridad pública, sin embargo, en el caso de las comunidades de población mayoritariamente mestiza no aplica, por tal motivo, resultaba imposible solucionar la problemática de la inseguridad pública aplicando sólo este precepto constitucional (Véase, CONSTITUCIÓN POLÍTICA ESTADOS UNIDOS MEXICANOS, 2016: 2729).
} 
formas de organización corporativa y vertical, creando un control estatal autoritario, limitando su capacidad autónoma de acción colectiva (MALDONADO, 2010: 284).

Pero en el estudio del Estado mexicano se ha desplazado la visión que lo analizaba como un Estado fuerte y autoritario, definido solamente por un control absoluto sobre el territorio y la población, a un Estado débil por su pérdida de soberanía y capacidad para regular o controlar los procesos socioeconómicos territoriales, no sólo formales sino informales, identificados estos últimos con la ilegalidad (ZERMEÑO, 1996).

Sin embargo, para Escalante el problema histórico del Estado mexicano radica en que su orden legal ha sido imaginario, es decir, no existe lo que muestra su debilidad, y al mismo tiempo, la fortaleza de formas organizativas sociales no cívicas sino corruptas o mafiosas (1999: 60-61).

Pero no se trata de caer en el dilema de Estado fuerte versus Estado débil sino de usar en el análisis la siguiente consideración: el Estado mexicano se ha trasformado a través del ejercicio de su legitimidad, basada en diversas formas autoritarias e ilegales, que relativizan las fronteras entre lo público y lo privado o mejor dicho entre lo lícito e ilícito (HIBOU, 2013: 19).

Lo anterior permite afirmar que el Estado mexicano ha realizado sus funciones reguladoras mediante diversas formas organizativas (privadas o sociales), que le permiten su reproducción o formación continua, lo que en ciertos territorios ilegales o zonas grises se ha manifestado por medio de su fuerza punitiva o como una complicidad entre las autoridades locales y las organizaciones que lucran con lo ilegal (GAMALLO, 2014: 60-61).

Según AUYERO, los territorios ilegales o zonas grises se caracterizan por su ambigüedad, donde no existen límites claros entre lo legal y lo ilegal y la reproducción de la autoridad se produce a través de relaciones clandestinas entre líderes, caciques, presidentes municipales, jefes policíacos, mafias (2007: 84).

El Estado mexicano ejerce sus funciones de gobernabilidad en las zonas grises, marcadas por la ambigüedad y la indefinición, lo que ha resultado favorable a los poderes locales, donde una parte de su fuerza radica en el negocio ilícito.

Por otro lado, en los territorios ilegales o zonas grises, los mecanismos de poder han permitido la normalización de la violencia a través de una convivencia conflictiva y cotidiana con la población.

Sin embargo, la vigilancia armada emerge cuando una parte de la población le disputa el poder coercitivo armado a las organizaciones criminales debido a que ésa coerción se 
transformó en un abuso, que atentó contra el patrimonio y la vida de los pobladores (GAMALLO, 2014: 47-55).

Considerando, según FOUCAULT (2011: 17-20), que la seguridad de la población en un territorio depende más del uso de los dispositivos de vigilancia y control porque castigan las conductas contrarias al orden social establecido.

A medida que aumenta el sentimiento colectivo de inseguridad se van mejorando los dispositivos de control de parte de los gobiernos, según LYON, para almacenar más información de los datos privados de los individuos criminalizados (2004: 135-149).

En algunas regiones mexicanas, la vigilancia armada comunitaria ha mostrado las limitaciones de la tecnología de la vigilancia en los territorios ilegales, concretado en el debilitamiento de los poderes ilegales, que regulan las actividades socioeconómicas locales, en complicidad con la autoridad local.

Por otro lado, la transnacionalización en la lucha contra el tráfico de estupefacientes ha influido en la configuración de territorios ilegales debido a que la economía formal local se colapsó con la apertura de la economía nacional, y la sobrevivencia de su población, fue dependiendo más de la siembra y venta de drogas demandas en el mercado internacional ${ }^{12}$.

En consecuencia, en las zonas grises, el negocio ilegal de las drogas ha organizado la dinámica cotidiana, mientras, la complicidad de las autoridades intentaba servir para controlar la violencia, usada para atentar contra la vida de los clasificados como enemigos y despojar también de sus propiedades a sus residentes (CAPORAL, 2013; JORQUERA, 2011).

Pero los testimonios periodísticos sobre las autodefensas de Tierra Caliente en Michoacán, permiten conocer algunas características de la organización social en algunas zonas grises, y a su vez, el papel de la autoridad en su reproducción.

La relación informal entre las autoridades y las organizaciones criminales en Tierra Caliente, considerada como un territorio o región ilegal, quedó de manifiesto en noviembre de 2007, cuando La Familia Michoacana, organizó una reunión con 14 alcaldes electos que gobernarían durante el periodo 2008-2011, para cobrarles el dinero prestado, que les había servido para financiar sus campañas electorales.

\footnotetext{
12 Por ejemplo, en Tierra Caliente, localizada en el estado de Michoacán, se configura por los municipios de Apatzingán, Parácuaro, Nueva Italia, Buena Vista, Tomatlán, Tepalcatepec, Aguililla, Gabriel Zamora y Churumuco, donde han surgido grupos de autodefensas que se les ha vinculado con los procesos derivados del narcotráfico, y la generalización de la violencia, acompañada con operaciones militares permanentes de parte del ejército mexicano (MALDONADO, 2010: 17).
} 
Entre los asistentes había 11 alcaldes que eran del Partido Revolucionario Institucional (PRI), uno de la alianza Partido Acción Nacional (PAN) y Partido Verde Ecologista de México (PVEM), otro representaba al PAN y el último surgió de la alianza PAN-PRI-PVEM (HERNÁNDEZ, 2013).

Antes, en diciembre de 2006, el gobierno emanado del PAN Felipe Calderón, aprobó la Ilamada Operación Conjunta Michoacán, que sirvió para legitimar la función punitiva estatal a través de una mayor presencia del ejército en el combate contra el narcotráfico y la delincuencia organizada de la región (NÚÑEZ, 2012: 61-63).

Más tarde, en mayo de 2009, el mismo presidente Calderón aprobó otro operativo militar y policiaco llamado el "michoacanazo", que fue usado para detener a funcionarios y presidentes municipales acusados de colaborar con el cártel de La Familia Michoacana.

Pero más tarde se supo que fue parte de la propaganda electoral panista, que buscaba desacreditar al Partido de la Revolución Democrática (PRD) mediante el encarcelamiento de 11 ediles que representaban a dicho partido en el ejercicio de su función pública.

De los 11 alcaldes del PRI acusados de tener vínculos con el crimen organizado, sólo se encarceló a Armando Medina Torres alcalde del municipio de Múgica, pero en 2011 fue liberado por falta de pruebas y en el año siguiente (2012) formó parte del gobierno estatal del PRI, encabezado por el entonces gobernador Fausto Vallejo, cuyo hijo, a través de un video subido a Youtube, se observaba negociando con el líder de la organización delictiva La Familia, Servando Gómez Martínez alias la Tuta, lo que más tarde provocó su detención y encarcelamiento (HERNÁNDEZ, 2013: 6-7).

Por otro lado, los cambios que han sufrido las organizaciones criminales dedicadas al narcotráfico en Tierra Caliente son resultado de divisiones internas, y de enfrentamientos armados con sus rivales, pero también de la manera en que han reorganizado a la policía estatal a través de sobornos, amenazas y agresiones contra los policías que no quieren cooperar. Esto ha sido importante porque se garantiza el libre tránsito o la organización del tráfico de drogas en el territorio mediante protección de sicarios que cobran una cuota por su servicio, al mismo tiempo, han apoyado el desarrollo de algunos proyectos comunitarios (MALDONADO, 2010).

En febrero de 2010 se tuvo conocimiento de que La Familia había creado sus propias clínicas de rehabilitación de adictos en más de seis poblaciones localizadas en la costa de Michoacán y sus alberges llamados Gratitud, donde atraían a los drogadictos mediante programas religiosos (...cuando) dejaban las drogas se les encomendaba trabajar como 
narcotraficantes o de lo contrario serían asesinados (HERNÁNDEZ, 2013: 9) $)^{13}$.

Así en los años 90 del siglo XX, pequeños grupos delictivos agrupados en el llamado Cártel del Milenio, controlaban el tráfico de drogas en Michoacán, pero su posterior transformación, primero en el cártel de La Familia y después en Los Caballeros Templarios a inicios del siglo XXI, se acompañó de una ideología fundamentalista cristiana, que predicaba el derecho divino a eliminar a sus enemigos, justificado mediante algunos pasajes de la Biblia (LOMNITZ, 2016).

Pero el fundamentalismo religioso de Los Caballeros Templarios demostró la fuerza de una ideología que intentaba sustituir a la familia mexicana en lo relacionado con la autoridad y la protección hacia sus miembros, buscando lealtad de los mismos a cambio de beneficios y seguridad en su vida y propiedades (LOMNITZ, 2016: 28-29).

Sin embargo, la dominación de Los Caballeros Templarios, según LOMNITZ, (2016: 36), en Tierra Caliente, se transformó en una ideología opresora sostenida por sus sicarios a través de las armas, donde el ejercicio de la violencia los hizo amos de la región y posteriormente en blanco de la rebelión de las autodefensas armadas comunitarias.

Por ello, en 2013, el surgimiento de las autodefensas en Tierra Caliente encontró su justificación en el discurso del entonces presidente municipal de Coalcomán, Rafael García Zamora: "iY era insoportable la situacióni A todos nos extorsionaban. Hasta en el municipio teníamos que darles $10 \%$ del presupuesto cada mes (...) Lo aceptamos...pero ya no lo hicimos (...porque) se metieron con muestras familias, violaban y se llevaban a nuestras esposas a nuestras hijas..." (GIL, 2013a: 6).

Fue entonces cuando se organizaron las autodefensas armadas, utilizando retenes, desde los poblados de Buenavista Tomatlán hasta Coalcomán, para vigilar y detener a los colaborares de Los Caballeros Templarios.

A su vez, hubo enfrentamientos armados con los sicarios de Los Caballeros Templarios, que por varias semanas bloquearon la entrada de las comunidades con camiones de carga hasta que arribaron 6 mil soldados para terminar con el bloqueo.

\footnotetext{
${ }^{13}$ La génesis de las organizaciones criminales muestran no sólo un cambio de nombre sino una disputa violenta para monopolizar la producción de drogas sintéticas y su tráfico hacia los Estados Unidos. Así como el uso de diferentes dispositivos para controlar la producción de la economía ilegal e integrar también a las autoridades y a la población a su dinámica (Véase, HERNÁNDEZ, 2013a: 8).
} 
Sin embargo, ésos 6 mil soldados también tenían la orden de desarmar a las autodefensas, lo que fue rechazado por las comunidades en conflicto con Los Caballeros Templarios.

Sobre todo, porque la entrega de armas significaba cederles a los militares la vigilancia de sus comunidades, sin embargo, aquéllos desconocían a los residentes que pertenecían a Los Caballeros Templarios.

A pesar de la anterior consideración, los militares y las fuerzas federales siguieron desarmando a las autodefensas, pero no combatían a los sicarios de Los Caballeros Templarios (GIL, 2013a: 7).

Después llegaron a un acuerdo con el general Sergio García Aragón debido a que las autodefensas habían detenido a 24 soldados en protesta por la detención de 4 integrantes de las mismas, acusados de portar armas de manera ilegal.

Pero se llegó al siguiente acuerdo: la mayoría de las autodefensas dejarían los puestos de revisión a los militares, lo que sería a cambio de la liberación de los 4 detenidos. Al mismo tiempo, sólo algunas autodefensas permanecerían en los retenes, acompañados de los militares para no permitirle el paso a los miembros de Los Caballeros Templarios, que vivían en las diferentes comunidades de Tierra Caliente (GIL, 2013b: 8).

Por otro lado, en la región de Tierra Caliente se legitimó la presencia de Los Caballeros Templarios porque como se ha argumentado es una zona gris o territorio ilegal, donde el Estado tiene una presencia parcial y ambigua, que no garantiza la seguridad, por tal motivo, sus pobladores en 2013 dijeron: “(...) los pistoleros de Los Caballeros Templarios Ilegaron a prometerles que los cuidarían (... de los criminales) A cambio les pedirían una cuota. La mayoría de los habitantes aceptó, sin saber que pronto sus pertenencias serían robadas, y sus familias (...serían) víctimas de la violencia” (GIL, 2013b: 9).

Esto mostró que la violencia en Tierra Caliente se ha reproducido a través de intersticios, localizados entre el Estado y el mercado, y que han favorecido la reproducción de acciones ilegales, que se han convertido en la base de la violencia armada (MALDONADO, 2010: 24).

En Tierra Caliente, la autodefensa armada se convirtió en un dispositivo de la vigilancia debido a que varios de sus integrantes formaron parte de Los Caballeros Templarios porque 
habitaban en las mismas comunidades ${ }^{14}$, y que fueron reclutados como desertores e informantes, ante la huida y abandono de algunas propiedades de los líderes del narcotráfico ${ }^{15}$.

Por ello, algunos miembros de las autodefensas se integraron a las labores de vigilancia, realizadas por la policía federal y el ejército. Para que más tarde el gobierno federal las convirtiera en guardias rurales, lo que legitimó la presencia coercitiva o punitiva del Estado mexicano en Michoacán.

Por otro lado, una iniciativa que nació de las mismas comunidades para coordinar territorialmente las acciones de las autodefensas fue El Consejo Ciudadano de Autodefensas y Comunitarios de Michoacán, donde uno de sus coordinadores el médico José Manuel Mireles Valverde, alcanzó un protagonismo importante al convertirse en un líder con influencia en la mayoría de los municipios de Tierra Caliente:

En la plaza principal de Tancítaro-municipio tomado por un nuevo grupo de autodefensa-encabeza una asamblea. Invita al presidente municipal (...) a participar, pero a él (...a Mireles Valverde) es a quien quieren escuchar y le ofrecen un micrófono. Lo rechaza...No necesito micrófono. Mi voz se oye lejos, en Estados Unidos, la ONU (...Organización de las Naciones Unidas), Europa...hasta en la Presidencia de la República (GIL, 2013b: 7-8).

Mireles decía que los grupos de autodefensa ciudadana eran un movimiento de "liberación social", que no estaba en contra del gobierno o del ejército porque sus enemigos eran los grupos del crimen organizado, en suma, iban contra la delincuencia en sus diversas modalidades: "No somos jueces, simplemente queremos que se vayan y los que se quieran quedar necesitan hacer cambio de su forma de vivir...no vamos a permitir la presencia de ninguna clase de criminales, mucho menos de parásitos sociales que abundan en todos lados" (GIL, 2013c: 9).

Sin embargo, acusaba a los tres niveles del gobierno de Michoacán de estar involucrados en el crimen organizado, lo que había causado, insistía Mireles, la creación de las autodefensas.

\footnotetext{
${ }^{14}$ Este hecho muestra lo siguiente: la información que poseían los ex integrantes de Los Caballeros Templarios resultó importante debido a que se transformó en un flujo que fortaleció el dispositivo de la vigilancia armada al convertirse en un comando de control (MATTELART y VITALIS, 2015: 91). Por tal motivo, los centros de detención de los ex informantes de Los Caballeros Templarios fueron importantes durante el conflicto debido a que "colaboraron" para ubicar a los criminales (CASTELLANOS, 2014).

15 Las autodefensas en Tierra Caliente aparecieron el 24 de febrero de 2013, antes en 2011 en el municipio indígena de Cherán, se había formado una policía comunitaria autónoma del municipio que se sigue gobernando mediante un consejo, sin alcalde ni cabildo. Se rumora que las autodefensas de Tierra Caliente tomaron en cuenta la experiencia autoorganizativa de los habitantes de Cherán.
} 
Lo anterior fue confirmado el 16 de marzo de 2012, cuando se reveló que el 13 de noviembre de 2011, antes de la celebración de las elecciones para gobernador, donde triunfó el candidato del PRI (Fausto Vallejo Figueroa) ${ }^{16}$, el secretario de gobierno (Jesús Reyna) se había reunido dos veces con el líder principal de Los Caballeros Templarios, Servando Gómez Martínez (la Tuta), donde también estuvo presente el alcalde de Tepalcatepec, Guillermo Valencia y el exdiputado local del PRI, José Trinidad Martínez Pasalagua (CASTELLANOS y GIL, 2013: 11-12).

En consecuencia, se debe de destacar que las acciones derivadas de la vigilancia armada de parte de los pobladores de Tierra Caliente, mostraron que los territorios ilegales son espacios donde la lógica de la violencia es una parte importante de los vínculos que organizan las relaciones sociales.

Desde el punto de vista de COLLINS (2008: 1-35) en los territorios ilegales o zonas grises existen condiciones que posibilitan el surgimiento de escenarios favorables a la violencia directa, es decir, al enfrentamiento armado ${ }^{17}$.

Por eso, la presencia gubernamental en Tierra Caliente no sólo fue a través del ejército y la policía federal; sino, por medio de la creación de la figura de comisionado para la Seguridad y Desarrollo Integral de Michoacán, en enero de 2014.

El comisionado, Alfredo Castillo ${ }^{18}$ tenía como propósito pacificar al estado mediante la creación de mejores condiciones de vida y de seguridad para la población michoacana (HERNÁNDEZ, 2014: 6).

Pero no hubo contención de la violencia debido a que las cifras de secuestros, robos y homicidios siguieron aumentando, lo que reforzó la siguiente tendencia general: a una mayor presencia de las fuerzas armadas en los territorios ilegales aumentaba el número de homicidios, lo que desde el punto de vista gubernamental, se ha interpretado como consecuencia de los

\footnotetext{
${ }^{16}$ El 18 de junio de 2014. Fausto Vallejo Figueroa renunció al gobierno de Michoacán por motivos de salud, antes había circulado en las redes sociales una foto de su hijo Rodrigo Vallejo Mora en compañía de Servando Gómez (La Tuta), líder de Los Caballeros Templarios, según un informe del gobierno federal Vallejo Mora usó sus lazos políticos para el lavado de dinero y como intermediario entre empresarios y políticos con las organizaciones del crimen organizado local (GIL, 2014c: 7).

17 Sobre todo, porque predominan los acuerdos informales apoyados en intereses particulares, transformados en compromisos, que en caso de no cumplirse no se invoca a la fuerza del Estado ni a la ley; sino, a un castigo ejercido a través de la violencia y la muerte en contra de la parte que no cumplió el compromiso (DOMíNGUEZ, 2015).

${ }^{18}$ Fue nombrado procurador de justicia de El Estado de México por el entonces gobernador de la entidad, Enrique Peña Nieto, en marzo de 2010, en el momento en que había una atención mediática nacional por el supuesto secuestro de la hija de los Gebara Farah, matrimonio de clase alta, pero su intervención fue polémica porque la hizo de manera errada y sospechosa, sin embargo, el caso llevó el nombre de la supuesta secuestrada (Paulette), que más tarde fue encontrada muerta en su propia habitación (MORENO, 2010: 22-23).
} 
enfrentamientos armados entre las diferentes organizaciones del narcotráfico que luchan por los altos beneficios derivados de un negocio ilegal e inestable como es el comercio de diferentes tipos de drogas (ESCALANTE, 2011: 37).

En Tierra Caliente, la llamada guerra contra el narcotráfico sólo sirvió para que el gobierno mexicano explicara la violencia como resultado de conflictos entre narcotraficantes, sin embargo, no consideró que en diferentes partes del país existen mercados de drogas muy atractivos, donde no hay violencia, como por ejemplo en la ciudad de México, lo que no se pudo ocultar porque a partir de 2008, aumentaron las tasas de homicidio en los estados, donde la seguridad pública fue militarizada (ESCALANTE, 2011: 40).

A partir de 2006 (año en que comenzó el operativo militar contra los narcotraficantes de Tierra Caliente) se incrementó la tasa de homicidios debido a que el 47\% se concentró en la región de Tierra Caliente, Tapaltepec y Costa del Pacífico: “(...) En 2008 y 2009 la tasa vuelve a subir (...) en el estado de Michoacán: primero, de 13 a 16, y de ahí a 23 homicidios por cada 100 mil habitantes" (ESCALANTE, 2011: 47).

Desde el punto de vista de ESCALANTE, el aumento en las tasas de homicidio en México no obedece a una sola causa: la presencia generalizada del crimen organizado, sino a la existencia de operativos militares que realizaron funciones de seguridad pública, lo que provocó el desplazamiento de las policías locales, que eran una fuerza regional que regulaba los mercados informales o ilegales de drogas y de mercancías provenientes del contrabando (2011: 49).

Su desaparición ha creado incertidumbre ${ }^{19}$ que puede transformarse en violencia, en un contexto donde existe una diversidad de sujetos que tienen armas para defender sus intereses particulares, sobre todo, cuando han dejado de funcionar algunos pactos informales (CHAPMAN, 2012; ALVARADO, 2012: 36-37).

Pero según SIMMEL (2010: 17-32), los acuerdos o pactos informales no excluyen el conflicto, sin embargo, ayudaban a la creación de estabilidad y certidumbre donde predomina un orden informal o ilegal, que en determinadas coyunturas, se podría transformar en violencia,

\footnotetext{
${ }^{19}$ Existe una fuerte relación entre la incertidumbre social y la violencia porque la estabilidad y la certeza se erosionó cuando despareció la base material para construir un futuro, lo que fue posible cuando el trabajo y su articulación a los derechos sociales originó protecciones estatales ante riesgos como el desempleo, la enfermedad o invalidez. Esto paulatinamente fue abandonado ante la transformación de la ideología neoliberal en política económica por parte de los diferentes gobiernos del mundo (Véase, KESSLER, 2013).
} 
creando situaciones de incertidumbre, vivida esta última como inseguridad pública (CASTEL, 2004: 75-81).

La generalización de la creencia colectiva de que la inseguridad pública era provocada por la debilidad estatal o por su ausencia, impulsada por el crimen organizado, que usaba la violencia para controlar los territorios ilegales, fue una ideología que permitió también a las autodefensas de Tierra Caliente legitimar sus tareas de vigilancia en sus propias comunidades.

Pero, en Tierra Caliente, la estrategia del gobierno federal de Enrique Peña Nieto se basó en reafirmar una nueva presencia punitiva gubernamental al transformar a los grupos de autodefensa en policías rurales, subordinados a las directrices de la Secretaría de Seguridad Pública de Michoacán, lo que sucedió el 10 de mayo de 2014, dejando fuera del proyecto a uno de sus principales líderes (José Manuel Mireles) que antes había declarado que los desaparecían porque el gobierno federal los consideraba una amenaza (GIL, 2014c: 6).

Pero más allá de representar una amenaza, el proyecto federal, que fue puesto en marcha por el comisionado Castillo, buscaba rehacer un nuevo acuerdo o pacto con las autodefensas, convertidas en policías rurales y ajenas a los intereses del narcotráfico, que se suponía que durante los combates se había debilitado la fuerza de los sicarios, y en consecuencia, se encontraban en vía de extinción.

En otras palabras, la nueva situación obligó al gobierno federal a reafirmar su presencia en Tierra Caliente, usando su capacidad punitiva, pero integrándola a la ejercida por las autodefensas, mostrando como dice COLLINS (2009: 110) que el delito es parte de la sociedad, y por tal motivo, existe la necesidad de legitimar de manera permanente el castigo ejercido por las instituciones estatales penales.

El nuevo orden policial no sólo era ajeno a la ley sino que el gobierno lo miraba como una oportunidad para establecer un pacto de seguridad pública, que excluía a los viejos actores (sobre todo, a las policías municipales), que se habían integrado al mercado ilegal de las drogas.

Entonces, lo que sucedió fue la aparición de un proceso de descolectivización ${ }^{20}$, que debilitó la capacidad organizativa de los individuos, es decir, disminuyó su capacidad para generar solidaridad; lo que también influyó en la desaparición de los acuerdos de seguridad pública, mantenidos por las corporaciones policíacas, que eran las responsables de regular los

\footnotetext{
${ }^{20}$ La solidaridad de los individuos es una manera de crear sociedad, en otras palabras, se produce un sentido de permanencia que se comparte mediante un destino común, basado en las protecciones derivadas de las instituciones estatales y de la familia, sin embargo, en México existen instituciones fallidas cuando no pueden cumplir con la tarea o función de generación de cohesión social; sobre todo, porque los individuos están abandonados a su propia suerte (CASTEL, 2014: 8-9).
} 
mercados ilegales, según CASTEL ésa situación (2004: 55-62) individualizó los riesgos, vividos como inseguridad pública, lo que obligó a los integrantes de algunas comunidades en Tierra Caliente a comprar protección a los grupos armados que controlaban los negocios privados ilegales y que tenían una presencia mayor en la vida económica de la región.

La transformación de las autodefensas en policías rurales significó también el fin del liderazgo de José Manuel Mireles, removido del Consejo General de Autodefensas a raíz de un accidente aéreo, y fue sustituido por Estanislao Beltrán (apodado "Papá Pitufo") quien interpretó dicho cambio como una manera de depurar a las autodefensas de personas que buscaban sólo su propio beneficio a través del uso de las armas.

Por eso, según "Papá Pitufo", la nueva policía rural era una vía de pacificación de la región porque se evitaría el surgimiento de organizaciones paramilitares y también se impediría, al mismo tiempo, que grupos armados de criminales se hicieran pasar por autodefensas (GIL, 2014d 7).

Sin embargo, las autodefensas encabezadas por Mireles se mantuvieron cohesionadas en su lucha contra el cártel de Los Caballeros Templarios, lo que cambió a inicios de 2014, no sólo porque Mireles salió de la escena del conflicto al sufrir un accidente aéreo y que lo tuvo fuera de las filas de los autodefensas, sino debido a que el entonces secretario de Estado de los Estados Unidos (John Kerry) expresó su preocupación por la situación de Michoacán, lo que obligó al gobierno de Enrique Peña Nieto a enviar 10 mil soldados y policías federales para detener a los líderes de Los Caballeros Templarios. Está acción fue acompañada del nombramiento de un comisionado federal (Alfredo Castillo); mientras, Mireles dejaba de ser el vocero oficial del Consejo General de Autodefensas y en su lugar fue nombrado "Papá Pitufo" que fue aceptado por el comisionado Castillo debido a la existencia de un acuerdo o pacto que buscaba el desarme de las autodefensas. Antes, Mireles había rechazado el pacto porque afirmaba que la delincuencia organizada continuaba en Michoacán (GIL, 2014d: 8).

De acuerdo con GIL (214d: 9), el comisionado Alfredo Castillo negoció con Estanislao Beltrán (alias "Papá Pitufo") y con Alberto Gutiérrez (alias el "comandante cero"), la salida de Mireles del Consejo y su destitución como su vocero, acusándolo “...de la muerte de cinco jóvenes en una barricada de Caleta de Campos, Lázaro Cárdenas, el pasado 27 de abril (de 2014)... (Además que hacía...) declaraciones que no (...iban) con la realidad. Anda en (la ciudad de) México sin permiso del Consejo, que lo integran 34 coordinadores, y habla mal del movimiento". 
La exclusión de Mireles del Consejo General de las Autodefensas no eliminó su presencia pública. Y en dos eventos masivos realizados en la ciudad de México, uno en el Polyforum Cultural Siqueiros, y el otro en la Universidad Autónoma de la Ciudad de México (UACM), en el mes de junio de 2014, repitió su crítica contra la estrategia gubernamental de convertir a las autodefensas en policías rurales, y por tanto, dijo que Michoacán no estaba en vías de pacificación a pesar de la propaganda mediática del presidente Peña Nieto y del comisionado Castillo porque les había puesto uniformes de policías rurales a algunos miembros de Los Caballeros Templarios; además, denunciaba que algunos de sus excompañeros habían aceptado de 3 a 4 millones de pesos para perdonar a algunos delincuentes e integrarlos a las filas de las autodefensas.

Finalmente, denunció que "Papá Pitufo", como parte de la dirección de los autodefensas, fue cooptado porque "(... de trabajar cortando limón) ahora tiene cuatro huertas de aguacate, siete huertas de limón y como 500 cabezas de ganado (...) y estrena vehículo cada mes (...) la estrategia del gobierno ha sido dividir a las autodefensas, armar a quienes han sido templarios y dejar a un lado a los verdaderos comunitarios para que luego se enfrenten y se eliminen ambos" (GIL, 2014e: 15).

Pero en ambos eventos anunció que quería formar el Frente Nacional de Autodefensas, es decir, reorganizar a la resistencia armada ciudadana o comunitaria presente en los diversos territorios ilegales en el plano nacional.

El conservar su fuerza como ex líder de las autodefensas michoacanas y su intensión de unificar a los diferentes esfuerzos armados comunitarios en los territorios ilegales mexicanos, constituyeron la causa que desembocó en su posterior detención.

El viernes 27 de junio de 2014, José Manuel Mireles y un grupo de sus seguidores, organizados como autodefensas, fueron detenidos en el puerto de Lázaro Cárdenas, en un operativo similar al que ha utilizado el gobierno federal para aprender a los jefes de los cárteles del narcotráfico, acusados de violar la Ley Federal de Armas y Explosivos, porque iban armados.

Mientras, el comisionado Alfredo Castillo, le imputó un delito adicional a Mireles: organizar a un nuevo grupo de autodefensa armada en la localidad de La Mira. Desde el día 10 de mayo de 2014, el comisionado del gobierno federal había advertido que serían detenidos las autodefensas que portaran armas y que no fueran parte de la policía rural (GIL, 2014f: 25-26) ${ }^{21}$.

\footnotetext{
${ }^{21}$ El 14 de abril de 2014, 20 líderes de las autodefensas de Michoacán, donde estaba José Manuel Mireles y Estanislao Beltrán, aceptaron con votación a mano alzada que el día 10 de mayo se daría el desarme, y
} 
Desde otro punto de vista, los territorios ilegales de Tierra Caliente han sido resultado del proceso económico neoliberal, como se ha mencionado, y que ha creado una situación de precariedad social, por tal motivo, los autodefensas en su primera reunión que tuvieron con el comisionado Castillo en la 43 Zona Militar, le pidieron hospitales, medicinas, escuelas, y que se liberara del dominio de Los Templarios los negocios de los limoneros; sobre todo, porque algunos dueños de plantíos de limones habían sido detenidos por las autoridades locales de manera injusta, acusándolos de delincuentes (DE MAULÓN, 2014: 17).

En resumen, en Tierra Caliente la estrategia punitiva del gobierno federal se basó también en la utilización de las autodefensas para combatir a Los Caballeros Templarios, así lo confirmó el comisionado Castillo: “...les dijimos que si trabajaban de la mano con nosotros podríamos concentrarnos en combatir a Los Templarios pero si ellos se iban por la libre (...las autodefensas), tendríamos que dedicarnos a combatirlos a ellos y a Los Templarios..." (DE MAULÓN, 2014: 18).

Por otro lado, en algunas comunidades, localizadas en Tierra Caliente la opción de la economía ilegal era una realidad (lo que abarcaba el tráfico de drogas), lo que involucró a varios miembros de las comunidades, y cuando apareció el conflicto entre autodefensas y Los Caballeros Templarios, algunos que habían sido "empleados" de Los Templarios, desertaron para integrarse a la comunidad, mediante su participación en las autodefensas.

Pero su reintegración a la comunidad se realizaba a través del perdón que se otorgaba, después de discutir el caso en una asamblea comunitaria, lo que dependía también de su grado de pertenencia al pueblo (ahí había nacido y vivía su descendencia y también habían vivido sus antepasados). Esto se transformó en un problema porque el impacto de las acciones ilícitas de los perdonados no era de la misma magnitud.

Un delito menor se equiparaba con uno de mayor magnitud, según el comisionado Castillo este proceder de las comunidades, introdujo en las autodefensas "infiltrados" al servicio de Los Caballeros Templarios, y en consecuencia, la autoridad federal decidió institucionalizar a las autodefensas como policías rurales para controlar la posibilidad de que las mismas se convirtieran en un apoyo renovado para el crimen organizado, lo que debería de ocurrir a partir del 10 de mayo (DE MAULÓN, 2014: 18-19).

Por otro lado, la vigilancia armada en Tierra Caliente mostró a la inseguridad pública, que sufrían las comunidades localizadas en los territorios ilegales, como un problema derivado

el comisionado Castillo advirtió que pasada ésa fecha se arrestaría a cualquier persona que portara armas (MARTÍNEZ y TORRES, 2014: A8). 
de la manera en que han participado en la organización de las economías ilegales, los grupos criminales, las policías locales, las autoridades, municipales y estatales, lo que ha configurado una nueva gobernanza ${ }^{22}$ a través de la función punitiva gubernamental, ligada a la lógica de la lucha transnacionalizada de los Estados Unidos contra el tráfico de drogas.

La institucionalización de los líderes de las autodefensas fue una condición que había creado el Estado mexicano para detener la posibilidad de alguna alternativa organizativa social, lo que ha favorecido la individualización de los riesgos y la violencia al considerar que esta última es un problema individual, que supuestamente desaparecería con la detención de los líderes de los negocios ilícitos del narcotráfico, confirmando que la sociedad mexicana sigue siendo organizada en mayor grado por las elites políticas y económicas (ZERMEÑO, 2005).

A su vez, la vigilancia social como un dispositivo de control funcionó también como un administrador del conflicto, donde la intervención común de las autoridades, Los Caballeros Templarios y los pobladores fue a través del uso de la fuerza letal contra los enemigos convertidos en culpables de las situaciones de incertidumbre, vividas como inseguridad pública, sin considerar que la misma en parte ha sido creada por la incapacidad de las instituciones estatales para establecer protecciones sociales organizadas por el principio de la sacralidad de la vida humana (KEANE, 2000: 18).

\section{CONCLUSIONES}

En Tierra Caliente, el dispositivo punitivo organizado por el Estado mexicano puede ser interpretado como un arreglo cupular, que permitía ejercer la violencia armada estatal para combatir a la delincuencia regional, lo que no ha sido nuevo por la existencia de una permisividad generalizada para que grupos armados particulares defiendan las propiedades de los productores de hortalizas, frutas de exportación y cría de ganado, ni para que intervengan en conflictos originados por el despojo de tierras contra los campesinos.

Lo nuevo de la situación es que la violencia criminal afecta a la población civil campesina que tiene que aprender a convivir y tolerarla y que es ejercida por los grupos criminales, asentados en las comunidades rurales, que han establecido una administración ilegal, desde donde se utiliza la fuerza armada para garantizar una seguridad pública, pero acorde con sus intereses particulares.

\footnotetext{
22 Desde el punto de vista neoliberal, el concepto de gobernanza señala que el Estado para gobernar depende de organizaciones sociales o de instituciones privadas porque su papel es mínimo o nulo en las decisiones (REQUENA, 2014: 47).
} 
La seguridad pública punitiva creaba una situación de excepción porque era ejercida por pistoleros y sicarios, que decidían sobre la vida y propiedad de los vecinos. Dentro de ésa situación de excepción se encontraban también los abusos que la policía y ejército realizaban porque gozaban de autonomía en el momento de impartir castigos, detenciones, desapariciones y muertes de los pobladores, que eran criminalizados por su supuesta complicidad en la reproducción del orden ilegal rural.

El aumento de tropas del ejército y de la policía federal fue un apoyo punitivo para la nueva figura del gobierno federal, llamada comisionado que realizó funciones de gobierno, dejando de lado la figura del gobernador, cuya tarea principal fue "normalizar" la situación de excepción de los territorios ilegales, donde los grupos armados de autodefensa combatieron a Los Caballeros Templarios.

La "normalización", desde un punto de vista general, fue la transformación de las autodefensas en policías rurales, encargados de la seguridad pública local, y subordinados ahora a las instituciones de seguridad pública estatal.

Por otro lado, el debilitamiento del cártel de Los Caballeros Templarios se puede considerar como el fin de un pacto entre los pobladores de las comunidades, las policías locales y las autoridades, que en el contexto de la lucha federal contra el narcotráfico, su presencia debería de ser como una fuerza pública legal.

En suma, el cártel de Los Caballeros Templarios perdió fuerza por las deserciones y la integración de algunos de sus miembros a los grupos de autodefensa, utilizando el perdón comunitario, mientras, otros huyeron acompañando a algunos de sus líderes.

Pero las divisiones entre los grupos de autodefensa, convertidos en policía rural, no desaparecieron sino que crearon un nuevo escenario de confrontación entre líderes ${ }^{23}$.

Sin embargo, la confrontación armada en los territorios ilegales no desapareció pero sí le permitió al comisionado Castillo cumplir con la tarea que el gobierno federal le encomendó:

${ }^{23}$ El 16 de diciembre de 2014, dos grupos de autodefensas, convertidos en policías rurales, uno encabezado por Hipólito Mora Chávez y el otro bajo el mando de Luis Antonio Torres (alias El Americano) se enfrentaron en la localidad de la Ruana en Michoacán. Murieron 11 personas y el comisionado Castillo les dio de plazo después de la navidad para que acudieran voluntariamente a la Procuraduría General de Justicia de Michoacán. Ambos se entregaron voluntariamente y fueron encarcelados, sin embargo, Hipólito denunció que Luis Antonio Torres seguía trabajando para el grupo de Los Caballeros Templarios (GARCíA, 2014: 18). Recordando que el 11 de marzo de 2014, Hipólito Mora había ingresado por primera vez al penal de Mil Cumbres acusado del homicidio de Rafael Sánchez Moreno y José Luis Torres Castañeda, integrantes de Los Caballeros Templarios, y que eran amigos de El Americano. A partir de ese hecho creció la rivalidad, aunque Mora fue dejado en libertad por falta de pruebas, el 16 de mayo de 2014. El americano no fue aceptado en las filas de las autodefensas de la Ruana por su pasado delictivo en el grupo delictivo Los Viagra, vinculado a Los Caballeros Templarios (MARTínEZ, 2014: 3). 
organizar una nueva fuerza punitiva rural de apoyo para cumplir de mejor manera la tarea punitiva gubernamental, usando el ejército y la policía federal contra los cárteles de la droga regional ${ }^{24}$.

La vigilancia armada se organizó en una situación, donde algunos de los miembros de las diferentes comunidades, habían realizado actividades ilícitas para Los Caballeros Templarios, en consecuencia, todos los vecinos eran vigilados por ellos mismos, aceptando perdonar a unos; mientras, a otros expulsarlos de las comunidades, utilizando los retenes que se construyeron en la entrada de cada pueblo, creando un dispositivo punitivo que no fue tan diferente al establecido por el gobierno mexicano.

\section{BIBLIOGRAFÍA}

AGAMBEN, Giorgio. What is an Apparatus? Stanford: Stanford University Press, 2009.

ALEXANDER, Jeffrey. The Civil Sphere. United States of America. Oxford: University Press, 2006.

ALVARADO, Arturo. El Tamaño del Infierno. Un estudio sobre la criminalidad en la Zona Metropolitana de la Ciudad de México. México: El Colegio de México, 2012.

AUYERO, Javier y BERTI, María Fernanda. La violencia en los márgenes. Una maestra y un sociólogo en el conurbado bonarense. Buenos Aires: Katz, 2013.

La zona gris. Violencia colectiva y política partidaria en la Argentina contemporánea. Buenos Aires: Siglo XXI Editores, 2007.

BAILEY, John. Crimen e impunidad. Las trampas de la seguridad en México. México: Debate, 2014.

BAUMAN, Zygmunt. Vidas desperdiciadas. La modernidad y sus parias. Barcelona: Paidós, 2013. Archipiélago de excepciones. Más comentarios de Giorgio Agamben y debate final. Buenos Aires: Katz, 2008.

\footnotetext{
${ }^{24}$ El 23 de diciembre de 2014, 100 personas ocuparon la alcaldía de Apatzingán en protesta porque el gobierno federal no los reconoció como grupo de seguridad. Dicho grupo especial era conocido como G250 (tenía sólo 250 miembros) y fue disuelto el 15 de diciembre. Mientras, el 6 de enero de 2014, fuerzas federales los desalojaron, decomisando sus armas y 23 vehículos, resultando muertas 9 personas, cuando intentaron recuperar sus camionetas. Además, detuvieron a 6 civiles que vendían mercancías a un costado del palacio municipal y hasta a personas que compraban juguetes (TORRES, 2015: A8). Este antecedente violento fue lo que permitió que el día 22 de enero de 2015, al secretario de Gobernación, Miguel Ángel Osorio Chong anunciara, en la ceremonia de evaluación del Plan Michoacán, el fin de la labor del comisionado Alfredo Castillo Cervantes.

Sin embargo, su actividad sería sustituida por un mando militar especial de las policías federales en Michoacán, encabezada por el general Felipe Gurrola Ramírez, y coordinadas con las autoridades estatales y municipales (MARTínEZ, 2015: 4).
} 
BAYÓN, María. La integración excluyente. Experiencias, discursos y representaciones de la pobreza urbana en México. México: UNAM/IIS/Bonilla Artigas Editores, 2015.

BERGER, Peter. Introducción a la Sociología. México: Limusa, 2013.

CAPORAL, José. El cártel de Neza, México: Random House Mondadori, 2013.

CASTELLANOS, Laura. "Nos van a mochar la cabeza", en http://archivo.eluniversal.com.mx/nación-mexico/2014/impreso/. Consultado el 2 de mayo de 2016, 2014.

CASTELLANOS, Francisco y GIL, José. Las autodefensas se fortalecen y multiplican. Proceso. No. 1934, 24 de noviembre, pp. 10-12, 2013.

CASTEL, Robert. De la protección social como derecho. En Robert Castel y Nicolas Duvoux. El porvenir de la solidaridad. Buenos Aires: Nueva Visión, 2014.

La Inseguridad Social ¿Qué es estar protegido? Buenos Aires: Manantial, 2004.

CHAPMAN, Debra. The Struggle for Mexico. State Corporatism and Popular Opposition. USA: McFarland, 2012.

COLLINS, Randall. Perspectiva Sociológica. Una introducción a la sociología no obvia. Buenos Aires: Universidad nacional de Quilmes, 2009.

Violence. A Micro-sociological Theory. Princeton: Princeton University Press, 2008.

CONSTITUCIÓN POLÍTICA ESTADOS UNIDOS MEXICANOS. México: Lectorum, 2017.

DELEUZE, Gilles. Negotiations 1972-1990. New York: Columbia University Press, 1995.

DE GIORGI, Alessandro. El gobierno de la excedencia. Postfordismo y control de la multitud. Madrid: Traficantes de Sueños, 2006.

DE MAULEÓN, Héctor. "Los secretos de Michoacán. Entrevista con Alfredo Castillo", Nexos. No. 44, diciembre, pp. 15-21, 2014.

DÉCOTTE, Jean-Louis. La época de los aparatos. Buenos Aires: Adriana Hidalgo editora, 2013.

DOMÍNGUEZ, Héctor. Nación criminal. Narrativas del crimen organizado y el Estado mexicano. México: Ariel, 2015.

ESCALANTE, Fernando. El crimen como realidad y representación. México: El Colegio de México, 2012. 2011.

"Homicidios 2008-2009. La muerte tiene permiso". Nexos. No. 397, enero, pp. 36-49,

La democracia mafiosa. México: Reflexiones sobre el cambio, A. C., 1999.

Ciudadanos imaginarios. Memorial de los afanes y desventuras de la virtud y apología del vicio triunfante en la República Mexicana-Tratado de moral pública. México: COLMEX, 1992. 
ESPINO, David. Aunque perdamos la vida. Viaje al corazón de las autodefensas. México: Grijalbo, 2016.

FERNÁNDEZ, Armando. Delito y criminalización en una sociedad global. En Armando Fernández Steinko (editor). Delincuencia, finanzas y globalización. Madrid: CIS, 2013.

FOESSEL, Michaël. Estado de vigilancia. Crítica de la razón securitaria. Madrid: Lengua de Trapo, 2011.

FOUCAULT, Michel. Seguridad, territorio, población. Buenos Aires: FCE, 2011.

GAMALLO, Leandro. Violencias colectivas. Linchamientos en México. México, FLACSO, 2014.

GARCÍA, Francisco. A prisión, Hipólito Mora y 26 ex autodefensas más. Milenio Diario, 28 de diciembre, p. 18., 2014.

GILBERT, Jorge. Introducción a la sociología. Santiago: LOM Ediciones, 2012.

GIL, José. Peña Nieto, tras los pasos de Calderón. Proceso, No. 1908, 26 de mayo, pp. 6-10, $2013 a$. 2013b.

Sólo el pueblo puede defender al pueblo. Proceso, No. 1934, 24 de noviembre, pp. 6-10, 2014c.

Un gobernador por el narco y para el narco. Proceso, No. 1964, 22 de junio, pp. 6-8, Las autodefensas, divididas y cooptadas. Proceso, No. 1959, 18 de mayo, pp. 6-9, 2014d. Michoacán sigue en guerra. Proceso, No. 1961, 1 de junio, pp. 13-15, 2014e.

Actos de resistencia por la "traición" contra Mireles. Proceso, No. 1965, 29 de junio, pp. 25-27, $2014 f$.

GLEDHILL, John. La cara oculta de la inseguridad en México. México: Paidós, 2017.

GOLUBOV, Nattie. El circuito de los signos, una introducción a los estudios culturales. México: Bonilla Artigas Editores/UNAM/CISAN, 2015.

GONZÁLEZ, Roberto. Temen a la inseguridad $70 \%$ de mexicanos que viven en ciudades. La Jornada, 9 de enero, p. 3, 2015.

HAESBAERT, Rogério. El Mito de la Desterritorialización. Del "Fin de los Territorios" a la Multiterritorialidad. México: Siglo XXI, 2011.

HARVEY, David. Spaces of Global Capitalism. Towards a Theory of Uneven Geographical Development. New York: Verso, 2006.

HERNÁNDEZ, Anabel. "Con todo y "virrey", el crimen se dispara en Michoacán. Proceso, No. 1970, 3 de agosto, pp. 6-9, 2014.

Quiénes y cómo gobiernan realmente en Michoacán. Proceso, No. 1931, 3 de Noviembre, pp. 6-10, 2013. 
HIBOU, Béatrice. De la privatización de las economías a la privatización de los estados. Análisis de la formación continua del Estado: México: FCE, 2013.

HONNETH, Axel. Reconocimiento y menosprecio. Sobre la fundamentación normativa de una teoría social. Barcelona: Katz, 2010.

ILLADES, Carlos y SANTIAGO, Teresa. Estado de guerra. De la guerra sucia a la narcoguerra. México: Era, 2014.

JORDÁN, Javier y BAQUÉS, Josep. Guerra de Drones. Política, tecnología y cambio social en los nuevos conflictos. Madrid: Biblioteca Nueva, 2014.

JORQUERA, Ramón. Ciudad del miedo. La seguridad y el capital social en las clases medias. Hermosillo: El Colegio de Sonora, 2011.

KEANE, John. Reflexiones sobre la violencia. Madrid: Alianza, 2000.

KEPEL, Gilles. La revancha de Dios. Cristianos, judíos y musulmanes a la reconquista del mundo. Madrid: Alianza Editorial, 2005.

KESSLER, Gabriel. Ilegalismos en tres tiempos. VV.AA, Individuación, precariedad, inseguridad ¿Desinstitucionalización del presente? Buenos Aires: Paidós, 2013.

LEMUS, Jesús. Tierra sin Dios. Crónica del desgobierno y la guerra en Michoacán. México: Grijalbo, 2015.

LOMNITZ, Claudio. La religión de Los Caballeros Templarios. Nexos, No. 463, julio, pp. 28-36, 2016.

LYON, David. Globalizing Surveillance. Comparative and Sociological Perspectives. International Sociology, Vol. 19, No. 2, June, pp. 135-149, 2004.

LYON, David. Surveillance after September 11. Oxford: Polity, 2003.

MARZANO, Michela. Programados para triunfar. Nuevo capitalismo, gestión empresarial y vida privada. México: Tusquets Editores, 2011.

MALDONADO, Salvador. Los márgenes del Estado mexicano. Territorios ilegales, desarrollo y violencia en Michoacán. Zamora: El Colegio de Michoacán, 2010.

MARTínEZ, Ernesto. Cierra el gobierno el ciclo de Castillo en Michoacán. La Jornada, 23 de enero, p. 4, 2015.

MARTínEZ, Ernesto. Mora ya declara en el penal de Mil Cumbres. La Jornada, 28 de diciembre, p. 3, 2014.

MATTELART, Armand y VITALIS, André. De Orwell al cibercontrol. Barcelona: Gedisa editorial, 2015. 

2014.

Por una mirada-mundo. Conversaciones con Michel Sénécal. Barcelona: Gedisa Editorial, MBEMBE, Achille. Necropolítica, España: melusina [sic], 2011.

MORENO, Martín. Paulette. Lo que no se dijo. Ellos sabían dónde estaba... México: Aguilar, 2010. NÚÑEZ, Ernesto. La tragedia del calderonismo. Crónica de un sexenio fallido. México: Grijalbo, 2012.

REQUENA, Carlos. Gobernanza. Reto en la relación Estado-Sociedad. México: LID editorial, 2014.

SÁNCHEZ, Alejandro. Yo, autodefensa. Así expulsamos a Los Templarios. Emequis, No. 320, 27 de febrero, pp. 36-49, 2014.

SIMMEL, Georg. El conflicto. Sociología del antagonismo. Madrid: Sequitur, 2010.

STAVRIDES, Stavros. Hacia una ciudad de umbrales. Madrid: Akal, 2016.

TELLO, Carlos, IBARRA, Jorge. La Revolución de los Ricos. México: Facultad de Economía/UNAM, 2012.

TRETÉ, Emiliano. Ecología del videoactivismo contemporáneo en México: alcances y limitaciones de las prácticas de resistencia en las redes digitales. En Francisco Sierra y David Montero (Eds.), Videoactivismo y movimientos sociales. Teoría y praxis de las multitudes conectadas. Barcelona: Gedisa editorial, 2015.

TIRADO, Francisco y DOMÉNECH, Miquel. Lo social y lo virtual. En Francisco Tirado y Miquel Doménech (Eds.), Lo social y lo virtual. Nuevas formas de control y transformación social. Barcelona: Editorial UOC, 2006.

TORRES, Raúl. Hay 6 quejas por detenciones arbitrarias en el operativo. El Universal, 10 de enero, p. A8, 2015.

WAQUANT, Loïc. Las cárceles de la miseria. Buenos Aires: Manantial, 2000.

WAJCMAN, Gérard. El Ojo Absoluto. Buenos Aires: Manantial, 2011.

ZERMEÑO, Sergio. La desmodernidad mexicana y las alternativas a la violencia y a la exclusión en nuestros días. México: Océano, 2005.

La sociedad derrotada. El desorden mexicano del fin de siglo. México: UNAM/Siglo XXI Editores, 1999.

Trabalho enviado em 16 de outubro de 2017.

Aceito em 26 de outubro de 2017. 